\title{
AS2077715: a novel antifungal antibiotic produced by Capnodium sp. 339855
}

\author{
Keisuke Ohsumi ${ }^{1}$, Teruhisa Masaki ${ }^{2}$, Shigehiro Takase ${ }^{1}$, Masato Watanabe ${ }^{1}$ and Akihiko Fujie ${ }^{1}$ \\ A novel antifungal agent, AS2077715, was isolated from the fermentation broth of a fungal strain (339855) identified as a \\ new Capnodium species based on morphological characteristics and large-subunit ribosomal DNA sequencing. AS2077715 was \\ isolated as a white powder via solvent extraction, HP-20 and ODS-B column chromatography and crystallization, and was \\ determined to have the molecular formula $\mathrm{C}_{25} \mathrm{H}_{41} \mathrm{NO}_{7}$. AS2077715 has a structure related to that of funiculosin, an inhibitor \\ of mitochondrial cytochrome $b c_{1}$ complex (complex III), and showed antifungal activity against Trichophyton species.
}

The Journal of Antibiotics (2014) 67, 707-711; doi:10.1038/ja.2014.69; published online 28 May 2014

\section{INTRODUCTION}

The prevalence of onychomycosis, also known as nail fungal infection and mainly caused by dermatophytes, has been estimated to range from 10 to $30 \%$ globally. ${ }^{1}$ Dermatophytes-mainly Trichophyton rubrum and Trichophyton mentagrophytes-are the predominant causative agents of onychomycosis, accounting for $\sim 50-90 \%$ of cases. $^{2-5}$ Clinical management of onychomycosis includes prescription systemic and topical treatment with antifungals such as terbinafine (an allylamine), amorolfine (a morpholine), itraconazole (a triazole) and ciclopirox (a hydroxypiridone). However, despite the availability of several therapeutic options, onychomycosis remains difficult to treat, and new drugs with improved safety and efficacy are needed. ${ }^{6}$

In our search for new anti-Trichophyton agents from microbial products, we identified the novel antifungal compound AS2077715 in the culture broth of a strain belonging to the Capnodium species (Figure 1). AS2077715 is a structural relative of funiculosin, an inhibitor of mitochondrial cytochrome $b c 1$ complex (complex III). Here, we studied the taxonomy and fermentation of the AS2077715-producing strain, as well as the isolation, physicochemical properties, structure and preliminary biological properties of AS2077715.

\section{RESULTS}

Taxonomy of strain 339855

Growth of strain 339855 on a potato dextrose agar was rather slow. Colonies grew to a diameter of $23-26 \mathrm{~mm}$ in 2 weeks at $25^{\circ} \mathrm{C}$. Surfaces of the colonies were felty and partially floccose. The entire margins of the colonies were in a circular pattern, and many radial sulcates were formed between the center and the margin. The felty parts of the colonies were grayish green $(30 \mathrm{~F} 8)$, whereas the floccose parts were dull grayish green (29E4). The underside of each colony was overall dark grayish green (28F4). Colonies reached $6-7 \mathrm{~mm}$ in diameter in 2 weeks at $30^{\circ} \mathrm{C}$, whereas no growth was observed at 5 or $37^{\circ} \mathrm{C}$. Growth of the strain on a corn meal agar was also slow, and colonies grew to a diameter of $22-24 \mathrm{~mm}$ in 2 weeks at $25^{\circ} \mathrm{C}$. Surfaces of the colonies were velvety. The entire margins of the colonies were in a circular pattern, and sulcates were not formed on the colonies. The color of colonies was grayish green (29F8-29F4). The colonies were not undulated, but smooth. Synnematous conidiophore was observed on colonies, and drop-like conidial masses were formed on the apexes of conidiophores. The underside of each colony was overall dark grayish green $(28 \mathrm{~F} 4)$. Colonies attained $6-9 \mathrm{~mm}$ in diameter in 2 weeks at $30^{\circ} \mathrm{C}$, whereas no growth was observed at 5 or $37^{\circ} \mathrm{C}$. The strain grew at temperatures between 12 and $25^{\circ} \mathrm{C}$, and the optimum growth temperature was in the range of $20-25^{\circ} \mathrm{C}$. Data on the growth temperatures were measured on potato dextrose agar. The $\mathrm{pH}$ at which the strain was capable of growing, measured in malt extract broth, was in the range of $2.0-11.5$, and the optimum growth $\mathrm{pH}$ was in the range of 5.5-6.2.

Morphological observations of strain 339855 using an optical microscope are shown in Figure 2. Vegetative hyphae were brown and $2.3-4.0 \mu \mathrm{m}$ thick. Chlamydospores were not observed. Conidiophores were not branched, but formed determinate synnemata. The overall length was $200-260 \mu \mathrm{m}$, and the thickness was $8-10 \mu \mathrm{m}$. The base of the synnemata formed stroma and widened to $30-40 \mu \mathrm{m}$. The synnemata was slightly swollen at the upper part and rather narrowed at the apex. Furthermore, several strands of setae were formed to surround the apex part. Colorless conidia were formed on the narrowed apex, and became a drop. The conidia were elliptical to cylindrical in shape $(3.2-3.6 \times 1.7-1.76 \mu \mathrm{m})$, with smooth surfaces.

The morphological features of strain 339855 resemble the genus Leptoxyphium $^{7}$ or Capnodium. 8,9 Both strains are known as plant diseases. We drew the phylogenetic tree using large-subunit rDNA sequences (Figure 3). Phylogenetic analysis showed that strain 339855 belongs to the clade of the genus Capnodium, so we identified strain 339855as Capnodium sp. 
(1)<smiles>CCC(C)CC(C)CCC1CCCC(c2c(O)c(C3=C(O)C(O)C(O)C3O)cn(C)c2=O)O1</smiles>

(2)<smiles>CC[C@H](C)C[C@@H](C)/C=C(\C)[C@H]1O[C@@H](c2c(O)c([C@@H]3[C@H](O)[C@@H](O)[C@@H](O)[C@@H]3O)cn(C)c2=O)CC=C1C</smiles>

Figure 1 Chemical structure of AS2077715 (1) and funiculosin (2).

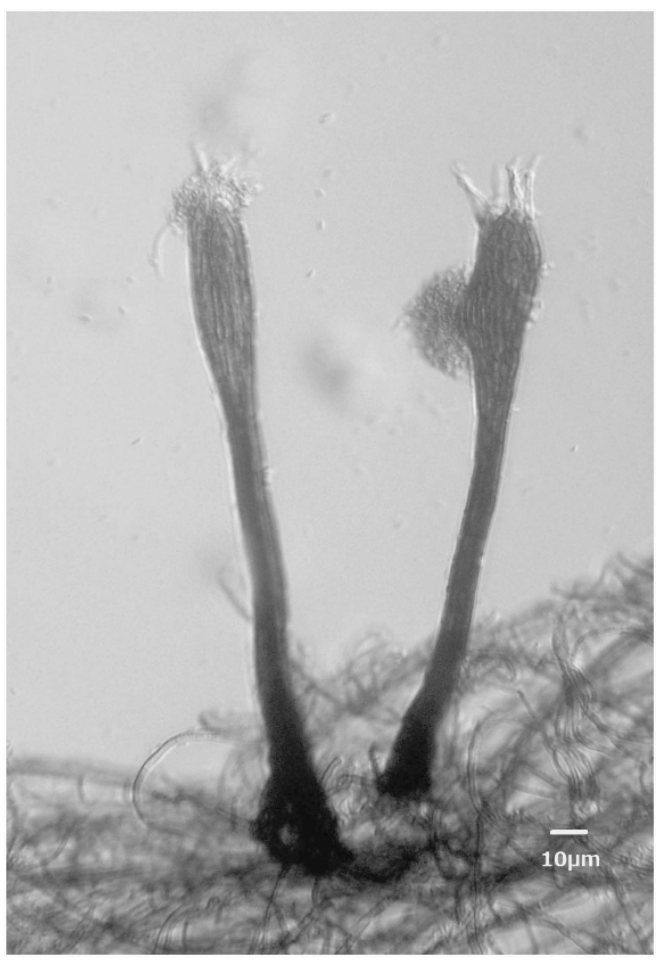

Figure 2 Morphological properties of strain 339855. A full color version of this figure is available at The Journal of Antibiotics journal online.

\section{Isolation and purification of AS2077715}

To isolate AS2077715 from the culture broth of Capnodium sp. 339855, an equal volume of acetone was added to the culture broth, and the resulting mixture was filtered with the aid of diatomaceous earth. The filtrate was diluted with twice the volume of water and passed through a DIAION HP-20 column (6.0 1; Mitsubishi Chemical, Tokyo, Japan) packed with water. The column was washed with $35 \%$ acetone and eluted with $60 \%$ acetone. The eluate (25l) was then diluted with twice the volume of water and passed through a Daisogel SP-120-ODS-B column (15/30 $\mu \mathrm{m}, 8.0$ l; Daiso, Osaka, Japan) packed with $25 \%$ acetonitrile. The column was eluted with $50 \%$ acetonitrile containing $0.01 \mathrm{~N} \mathrm{HCl}$. The active fractions were then diluted with an equal volume of water and passed through a Sepabeads SP850 column (1.01; Mitsubishi Chemical) packed with 25\% acetonitrile. The column was washed with water and eluted with ethyl acetate. The eluate was dried over $\mathrm{Na}_{2} \mathrm{SO}_{4}$ and concentrated in vacuo. The residue was dissolved in $5 \mathrm{ml}$ of methanol and $5 \mathrm{ml}$ of ethyl acetate, and combined with $50 \mathrm{ml}$ of $\mathrm{n}$-hexane to give crystals. The crystals were filtered and dried to give $17.6 \mathrm{~g}$ of AS2077715 as a white powder.

\section{Physico-chemical properties and structural elucidation of AS2077715}

The physico-chemical properties of AS2077715 are summarized in Table 1. AS2077715 was soluble in methanol, acetonitrile, chloroform, ethyl acetate and dimethyl sulfoxide and insoluble in water and $n$-hexane. The UV absorption maxima of purified AS2077715 occurred at $290.5 \mathrm{~nm}$, and a molecular ion peak at $\mathrm{m} / \mathrm{z} 468$ $\left([\mathrm{M}+\mathrm{H}]^{+}\right)$was detected in the ESI-MS spectrum (data not shown).

The molecular formula of AS2077715 was determined to be $\mathrm{C}_{25} \mathrm{H}_{41} \mathrm{NO}_{7}$ based on HRESI-MS and ${ }^{13} \mathrm{C}$ NMR data (Table 2). ${ }^{1} \mathrm{H}$ NMR spectrum of AS2077715 showed the compound to be a natural product, structurally related to funiculosin, an antibiotic isolated form Penicillium funiculosum Thom. ${ }^{10}$ The ${ }^{13} \mathrm{C}$ NMR data of 5-(2,3,4,5-tetrahydroxycyclopentyl)-4-hydroxy-2-pyridinone moiety of AS2077715 were in good agreement with those of funiculosin. The difference between AS2077715 and funiculosin resided in the alkyl side chain. Therefore, elucidation of the structure of AS2077715 was focused on the side chain, although ${ }^{1} \mathrm{H}$ signal overlapping of $8-\mathrm{H}_{2}, 9-\mathrm{H}_{2}, 10-\mathrm{H}_{2}$ and $13-\mathrm{H}_{2}$ made structure elucidation difficult. Analysis of HSQC-TOCSY data coupled with COSY and HSQC revealed the sequence $\mathrm{CH}(7)-\mathrm{CH}_{2}(8)-\mathrm{CH}_{2}(9)-\mathrm{CH}_{2}(10)-\mathrm{CH}(11)-$ $\mathrm{CH}_{2}(12)-\mathrm{CH}_{2}(13)$-. Oxymethine proton $7-\mathrm{H}$ at 4.94 p.p.m. showed HMBC correlation to $\mathrm{C}-11\left(\delta_{\mathrm{C}} 80.0(\mathrm{~d})\right)$ and $11-\mathrm{H}$ at 3.51 p.p.m. 


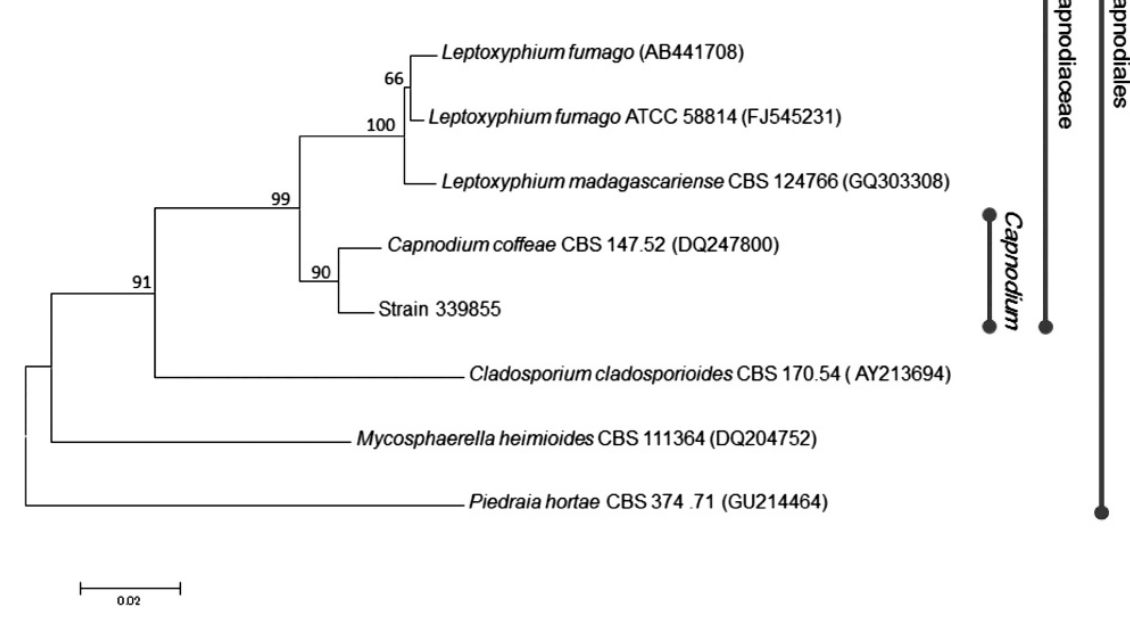

Figure 3 Phylogenetic tree based on large-subunit ribosomal DNA sequences. A full color version of this figure is available at The Journal of Antibiotics journal online.

\section{Table 1 Physico-chemical properties of AS2077715}

\begin{tabular}{|c|c|}
\hline Appearance & White powder \\
\hline Molecular formula & $\mathrm{C}_{25} \mathrm{H}_{41} \mathrm{NO}_{7}$ \\
\hline Molecular mass (g mol) & 467 \\
\hline \multicolumn{2}{|l|}{$H R-M S(m / z)$} \\
\hline Found $(\mathrm{M}+\mathrm{H})^{+}$ & 468.2965 \\
\hline Calculated $(\mathrm{M}+\mathrm{H})^{+}$ & 468.2961 \\
\hline$[\alpha]_{D}\left(23^{\circ} \mathrm{C}, \mathrm{MeOH}\right)$ & $-120^{\circ}$ (с 0.5$)$ \\
\hline UV $\lambda_{\max }(\mathrm{MeOH}) \mathrm{nm}(\varepsilon)$ & 233(sh), 290.5 (6100) \\
\hline Solubility: soluble & $\mathrm{CH}_{3} \mathrm{OH}, \mathrm{CH}_{3} \mathrm{CN}, \mathrm{EtOAc}, \mathrm{CHCl}_{3}$ and DMSO \\
\hline insoluble & $n$-hexane, water \\
\hline HPLC retention time $(\min )^{a}$ & 7.0 \\
\hline $\mathrm{IR} v_{\max } \mathrm{cm}^{-1}$ & $\begin{array}{l}3480,2980,2930,1730,1710,1650 \\
1620,1460,1380,1160 \text { and } 1140\end{array}$ \\
\hline
\end{tabular}

aRetention time obtained by Mightysil RP-18 GP 150-4.6 (5 $\mu \mathrm{m}$, Kanto Chemical), 55\% aq $\mathrm{CH}_{3} \mathrm{CN}$, flow rate $1 \mathrm{ml} \mathrm{min}^{-1}$.

showed HMBC cross-peak to C-7 $\left(\delta_{\mathrm{C}} 78.1(\mathrm{~d})\right)$, indicating the presence of a tetrahydropyran ring. $\mathrm{HMBC}$ coupling from $14-\mathrm{CH}_{3}$ $\left(\delta_{\mathrm{H}} 0.83\right)$ to the methylene at C-13 $\left(\delta_{\mathrm{C}} 33.2(\mathrm{t})\right)$ completed the side chain structure as shown in Figure 4 . The linkage between $\mathrm{C}-3$ and C-7 was indicated by HMBC couplings from $7-\mathrm{H}$ to $\mathrm{C}-2\left(\delta_{\mathrm{C}} 161.4\right.$ $(\mathrm{s}))$, C-3 $\left(\delta_{\mathrm{C}} 110.1(\mathrm{~s})\right)$ and $\mathrm{C}-4 \quad\left(\delta_{\mathrm{C}} 162.5(\mathrm{~s})\right)$, completing elucidation of the gross planar structure of AS2077715 (Figure 1).

\section{Antifungal activity of AS2077715}

The antifungal activity of AS2077715 against several fungi is shown in Table 3. AS2077715 showed potent antifungal activity against Trichophyton species but except for Cryptococcus neoformans, not against any other fungi tested at levels up to $2.5 \mu \mathrm{g} \mathrm{ml}^{-1}$. AS2077715 and funiculosin had the same spectrum of antifungal activity.

\section{DISCUSSION}

In this paper, we presented the isolation and characterization of a novel antifungal antibiotic, AS2077715, isolated from the fermentation broth of the strain 339855, which was identified as a species of Capnodium based on morphological characterization and DNA sequence results. We identified the structure of the novel antifungal compound AS2077715 in the culture broth of strain 339855 and demonstrated that this compound has strong activity against Trichophyton species.

AS2077715 was shown to be an analog of funiculosin, an antibiotic isolated form Penicillium funiculosum Thom. ${ }^{10}$ AS2077715 and funiculosin have the same pyridone and cyclopentane rings, differing only in the alkyl side chain. Similar to funiculosin, AS2077715 showed potent antifungal activities against Trichophyton species and C. neoformans and no activities against other fungi. These compounds showed no activities against facultative Gram-positive cocci or facultative and aerobic Gram-negative bacteria, with MICs of $>12.5 \mu \mathrm{g} \mathrm{ml}^{-1}$ (data not shown). These results suggest that the difference in the side chains of these compounds induce no differences in antimicrobial activities.

From the structural similarity to funiculosin, AS2077715 is expected to be an inhibitor of complex III. We plan to evaluate the in vitro and in vivo activities of AS2077715 against T. mentagrophytes, and will describe the findings in a subsequent paper.

\section{METHODS}

\section{Taxonomic study}

Strain 339855 was isolated using a moist chamber method from a fallen leaf from Zelkova serrata, which was collected at Youroukeikoku in Otaki-Machi, Isumi-gun, Chiba, Japan. Media for the taxonomic study of the strain were purchased from Becton, Dickinson, and Company (Franklin Lakes, NJ, USA). The morphological observations were made from cultures grown on corn meal agar after 14 days' cultivation at $25^{\circ} \mathrm{C}$, using an optical microscope. The color descriptions were based on the Methuen Handbook of Colour. ${ }^{11}$ The largesubunit rDNA sequence was determined via the method described by O'Donnell. ${ }^{12}$ The large-subunit rDNA sequences of type strains were obtained from DDBJ database (http://www.ddbj.nig.ac.jp/), and the MEGA program (version 5.22, http://www.megasoftware.net/) was used to draw the phylogenetic tree.

The DDBJ/GenBank/EMBL accession number for the large-subunit rDNA sequence of strain 339855 is AB894361.

\section{Fermentation}

A loopful of the slant culture of strain 339855 was inoculated into $30 \mathrm{ml}$ of sterilized seed culture medium, consisting of $2 \%$ cornstarch, $1 \%$ glycerin, $1 \%$ sucrose, $1 \%$ gluten meal, $1 \%$ pharmamedia (Archer Daniels Midland, Decatur, IL, USA), and $0.25 \%$ Tween 80 , in a wide-mouth 100 -ml Erlenmeyer flask. 
Table $21 \mathrm{H}(500 \mathrm{MHz})$ and ${ }^{13} \mathrm{C}(125 \mathrm{MHz})$ NMR data of AS2077715 in $\mathrm{CDCl}_{3}$

\begin{tabular}{|c|c|c|}
\hline \multirow[b]{2}{*}{ Position } & \multicolumn{2}{|c|}{ AS2077715 } \\
\hline & $\delta_{C}(m)$ & $\delta_{H}(m, J)$ \\
\hline 2 & $161.4(\mathrm{~s})$ & \\
\hline 3 & 110.1 (s) & \\
\hline 4 & $162.5(\mathrm{~s})$ & \\
\hline 5 & $107.2(\mathrm{~s})$ & \\
\hline 6 & $137.2(d)$ & $7.87(\mathrm{~s})$ \\
\hline 7 & $78.1(d)$ & $4.94(\mathrm{dd}, 11$ and 2) \\
\hline 8 & $30.2(t)$ & $2.04(\mathrm{~m}), 1.45(\mathrm{~m})$ \\
\hline 9 & $23.1(t)$ & $1.88(\mathrm{~m}), 1.70(\mathrm{~m})$ \\
\hline 10 & $31.4(t)$ & $1.70(\mathrm{~m}), 1.30(\mathrm{~m})$ \\
\hline 11 & $80.0(\mathrm{~d})$ & $3.51(\mathrm{~m})$ \\
\hline 12 & $33.9(\mathrm{t})$ & $1.54(\mathrm{~m}), 1.52(\mathrm{~m})$ \\
\hline 13 & $33.2(t)$ & $1.37(\mathrm{~m}), 1.12(\mathrm{~m})$ \\
\hline 14 & $30.1(d)$ & $1.45(\mathrm{~m})$ \\
\hline 15 & $44.1(t)$ & $1.06(\mathrm{~m}), 1.05(\mathrm{~m})$ \\
\hline 16 & $31.7(d)$ & $1.38(\mathrm{~m})$ \\
\hline 17 & $30.4(t)$ & $1.26(\mathrm{~m}), 1.13(\mathrm{~m})$ \\
\hline 18 & $11.4(q)$ & $0.86(3 \mathrm{H}, \mathrm{t}, 7.5)$ \\
\hline $1^{\prime}$ & $39.7(d)$ & $2.88(\mathrm{~m})$ \\
\hline $2^{\prime}, 5^{\prime}$ & $\begin{array}{l}74.4(d) \\
74.4(d)\end{array}$ & $4.40(2 \mathrm{H}, \mathrm{m})$ \\
\hline $3^{\prime}, 4^{\prime}$ & $\begin{array}{l}70.0(\mathrm{~d}) \\
70.0(\mathrm{~d})\end{array}$ & $4.10(2 \mathrm{H}, \mathrm{m})$ \\
\hline $\mathrm{N}-\mathrm{CH}_{3}$ & $37.2(q)$ & $3.49(3 \mathrm{H}, \mathrm{s})$ \\
\hline $14-\mathrm{CH}_{3}$ & $19.4(q)$ & $0.83(3 \mathrm{H}, \mathrm{d}, 6.5)$ \\
\hline $16-\mathrm{CH}_{3}$ & $19.0(q)$ & $0.80(3 \mathrm{H}, \mathrm{d}, 6.5)$ \\
\hline $4-\mathrm{OH}$ & & 10.09 (s) \\
\hline $2^{\prime}-\mathrm{OH}$ & & $3.40(d, 5)$ \\
\hline $5^{\prime}-\mathrm{OH}$ & & $3.39(d, 5)$ \\
\hline $3^{\prime}-\mathrm{OH}$ & & $3.53(d, 5)$ \\
\hline $4^{\prime}-\mathrm{OH}$ & & $3.50(d, 5)$ \\
\hline
\end{tabular}
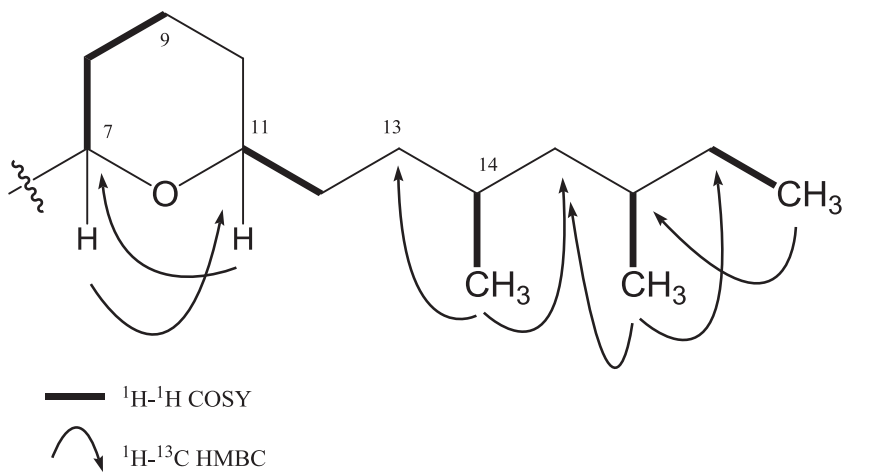

Figure 4 Structure elucidation of the side chain of AS2077715.

The flask was incubated at $25^{\circ} \mathrm{C}$ for 4 days on a rotary shaker $(220$ r.p.m., $5.1-\mathrm{cm}$ throw) and then inoculated (2\%) into $150 \mathrm{ml}$ of the same sterilized medium in each of three 500-ml Erlenmeyer flasks, which were then incubated at $25^{\circ} \mathrm{C}$ for 3 days on a rotary shaker ( 220 r.p.m., $5.1-\mathrm{cm}$ throw). The resultant seed culture was inoculated into a 30-1 stainless steel jar fermenter containing 201 of sterile production medium, which consisted of $6 \%$ soluble starch, $4 \%$ glucose, $2 \%$ yeast extract, $1 \% \mathrm{~K}_{2} \mathrm{HPO}_{4}, 0.02 \% \mathrm{MgSO}_{4}, 0.05 \%$ Adekanol LG-109 defoaming agent (ADEKA, Tokyo, Japan) and 0.05\% Silicone KM-70 defoaming agent (Shin-Etsu Chemical, Tokyo, Japan). Fermentation was
Table 3 Antifungal activity of AS2077715 against Trichophyton spp. and other fungi

\begin{tabular}{lccl}
\hline & \multicolumn{3}{c}{ MIC $\left(\mu g \mathrm{ml}^{-1}\right)$} \\
\cline { 2 - 4 } Test organism & AS2077715 & funiculosin & terbinafine \\
\hline Trichophyton mentagrophytes FP2103 & 0.08 & 0.08 & 0.01 \\
T. rubrum FP596 & 0.08 & 0.08 & $\mathrm{ND}$ \\
Aspergillus fumigatus FP1305 & $>2.5$ & $>2.5$ & $\mathrm{ND}$ \\
Rhizopus oryzae FP1988 & $>2.5$ & $>2.5$ & $\mathrm{ND}$ \\
Pseudallescheria boydii FP1987 & $>2.5$ & $>2.5$ & $\mathrm{ND}$ \\
Fusarium solani FP1930 & $>2.5$ & $>2.5$ & $\mathrm{ND}$ \\
Candida albicans FP633 & $>2.5$ & $>2.5$ & $\mathrm{ND}$ \\
C. krusei FP1979 & $>2.5$ & $>2.5$ & $\mathrm{ND}$ \\
C. glabrata FP1944 & $>2.5$ & $>2.5$ & $\mathrm{ND}$ \\
C. tropicalis FP1589 & $>2.5$ & $>2.5$ & $\mathrm{ND}$ \\
C. guilliermondii FP2086 & $>2.5$ & $>2.5$ & $\mathrm{ND}$ \\
C. parapsillosis FP1980 & $>2.5$ & $>2.5$ & $\mathrm{ND}$ \\
Cryptococcus neoformans FP1739 & 1.3 & 2.5 & ND \\
\hline
\end{tabular}

Abbreviation: ND, not determined.

carried out at $25^{\circ} \mathrm{C}$ for 6 days under aeration of $201 \mathrm{~min}^{-1}$, an inner pressure of $1.0 \mathrm{~kg} \mathrm{~cm}^{-2}$ and agitation at 200 r.p.m.

\section{HPLC Analysis}

Detection of AS2077715 from the fermentation broth and the fractions under purification was monitored via HPLC using a reverse-phase column (Mightysil RP-18 GP 150-4.6 $(5 \mu \mathrm{m})$; Kanto Chemical, Tokyo, Japan). An aqueous acetonitrile solution $(60 \%)$ was used as the mobile phase at a flow rate of $1.0 \mathrm{ml} \mathrm{min}{ }^{-1}$, and detection wavelength was set at $210 \mathrm{~nm}$.

\section{General experimental procedures}

High-resolution mass spectra were measured using an LCMS-IT-TOF spectrometer (Shimadzu, Kyoto, Japan). UV/Visible spectra were recorded with a UV-2500 PC (Shimadzu). Optical rotations were measured with a SEPA-500 polarimeter (Horiba, Kyoto, Japan). IR spectra were recorded with a Spectrum 65 FT-IR spectrometer (PerkinElmer, Waltham, MA, USA). NMR spectra, ${ }^{1} \mathrm{H}(500 \mathrm{MHz})$ and ${ }^{13} \mathrm{C}(125 \mathrm{MHz})$, were recorded on an AVANCE 500 spectrometer (Bruker, Yokohama, Japan).

\section{Antifungal activity}

Funiculosin was prepared in our laboratories. Rhizopus oryzae FP1988, Pseudallescheria boydii FP1987, Fusarium solani FP1930, Candida albicans FP633, C. krusei FP1979, C. glabrata FP1944, C. tropicalis FP1589, C. guilliermondii FP2086 and C. parapsillosis FP1980, which are clinical isolates deposited in our laboratory, ${ }^{13}$ were incubated in yeast-maltose broth for $24 \mathrm{~h}$ at $30{ }^{\circ} \mathrm{C}$ without shaking. Cryptococcus neoformans FP1739 (deposited in our laboratory) was cultured in yeast-maltose broth for $20 \mathrm{~h}$ at $30^{\circ} \mathrm{C}$ with shaking (250 r.p.m.). A cell suspension was prepared by washing the cultured cells once with sterile saline. Aspergillus fumigatus FP1305, Trichophyton mentagrophytes FP2103 and T. rubrum FP596 (deposited in our laboratory) were cultured on a potato dextrose agar slant for 4 days at $37^{\circ} \mathrm{C}$, and spores were then harvested in sterile saline and filtered through gauze. The antimicrobial activity of AS2077715 was measured via the micro-broth dilution method using 96-well culture plates and RPMI 1640 medium (Invitrogen, Tokyo, Japan) lacking sodium bicarbonate and supplemented with L-glutamine, buffered to $\mathrm{pH} 7.0$ with $0.165 \mathrm{M}$ MOPS. Yeast nitrogen base-glucose medium and modified Sabouraud dextrose medium, which was composed of $0.1 \%$ glucose, $0.2 \%$ bacto tryptone, $0.2 \% \mathrm{~K}_{2} \mathrm{HPO}_{4}, 0.005 \% \mathrm{MgSO}_{4}$ and $0.005 \% \mathrm{CaCl}_{2}$, were used to measure the antifungal activity of AS2077715 against C. neoformans and Trichophyton species, respectively. For measurements, the test fungus was inoculated into each well at a final concentration of $1 \times 10^{5}$ colony-forming units per well. The plates were incubated for $48 \mathrm{~h}$ at $30^{\circ} \mathrm{C}$ for Trichophyton species, $48 \mathrm{~h}$ at $37^{\circ} \mathrm{C}$ for C. neoformans or $20 \mathrm{~h}$ at $37^{\circ} \mathrm{C}$ for all other strains. 
MIC, which was the lowest concentration needed to completely inhibit fungal growth, was determined by microscopic observation.

1 Gupta, A. K. \& Simpson, F. C. New therapeutic options for onychomycosis. Expert. Opin. Pharmacother. 13, 1131-1142 (2012).

2 Faergemann, J. \& Baran, R. Epidemiology, clinical presentation and diagnosis of onychomycosis. Br. J. Dermatol. 149(Suppl 65), 1-4 (2003).

3 Foster, K. W., Ghannoum, M. A. \& Elewski, B. E. Epidemiologic surveillance of cutaneous fungal infection in the United States from 1999-2002. J. Am. Acad. Dermatol. 50, 748-752 (2004).

4 Ghannoum, M. A. et al. A large-scale North American study of fungal isolates from nails: the frequency of onychomycosis, fungal distribution, and antifungal susceptibility patterns. J. Am. Acad. Dermatol. 43, 641-648 (2000).

5 Kaur, R., Kashyap, B. \& Bhalla, P. Onychomycosis-epidemiology, diagnosis and management. Indian J. Med. Microbiol. 26, 108-116 (2008).
6 Arrese, J. E. \& Pierard, G. E. Treatment failures and relapses in onychomycosis: a stubborn clinical problem. Dermatology 207, 255-260 (2003).

7 Seifert, K., Morgan-Jones, G., Gams, W. \& Kendrick, B. The Genera of Hyphomycetes, CBS Biodiversity Series 9 (CBS-KNAW Fungal Biodiversity Center, Utrecht, The Netherlands, 2011).

8 Takao, K. Illustrated Genera of Plant Pathogenic Fungi in Japan (Zenkoku Noson Kyoiku Kyokai Publishing, Tokyo, Japan, 1992).

9 Mycota Iryuda. Mycological volunteer group. Kanagawa Prefectural Museum of Natural History 1, 14-15 (2011).

10 Ando, K. et al. Funiculosin, a new antibiotic. II. Structure elucidation and antifungal activity. J. Antibiot. 31, 533-538 (1978).

11 Kornerup, A., Wanscher, J. H. \& Pavey, D. Methuen Handbook of Colour 3rd edn (introduced and revised by Don Pavey), 252 (Hastings House, 1987).

12 O'Donnell, K. Ribosomal DNA internal transcribed spacers are highly divergent in the phytopathogenic ascomycete Fusarium sambucinum (Gibberella pulicaris). Curr. Genet. 22, 213-220 (1992).

13 Tawara, S. et al. In vitro activities of a new lipopeptide antifungal agent, FK463, against a variety of clinically important fungi. Antimicrob. Agents Chemother. 44, 57-62 (2000) 